\title{
Analysis of variability of plasma leptin and lipids concentration in relations to glycolytic potential, intramuscular fat and meat quality in P76 pigs
}

\section{W. Przybylski ${ }^{1}$, J. Gromadzka-Ostrowska ${ }^{2}$, E. Olczak ${ }^{1}$, D. Jaworska ${ }^{1}$, S. Niemyjski ${ }^{3}$ and V. Santé-Lhoutellier ${ }^{4}$}

\author{
Warsaw University of Life Sciences, \\ ${ }^{1}$ Faculty of Human Nutrition and Consumer Science, \\ Department of Engineering and Catering Technology, \\ ${ }^{2}$ Faculty of Human Nutrition and Consumer Science, Department of Dietetics \\ Nowoursynowska 159C, 02-787 Warszawa, Poland \\ ${ }^{3}$ PenArLan \\ Spółdzielcza 2a, 64-100 Leszno, Poland \\ ${ }^{4}$ Quality of Animal Products INRA \\ 63122 Saint Genés Champanelle, France
}

(Received 8 July 2008; revised version 2 December 2008; accepted 20 March 2009)

\begin{abstract}
The aim of the study was the analyse of the variability and relationship between plasma leptin and lipids concentration, glycolytic potential, intramuscular fat and meat quality in P76-PenArLan hybrids pigs. The research was carried out on 30 pigs (18 boars and 12 gilts). In blood plasma, taken in vivo, leptin, triglycerides, total and HDL cholesterol were measured. Slaughter value of carcass was evaluated by CGM apparatus. On the basis of $\mathrm{pH}$ value, meat colour and natural drip loss, meat quality was estimated. Intramuscular fat and glycolytic potential was also determined. Obtained results showed a significant inversely relationship between: a. plasma leptin level and backfat thickness and $b$. between intramuscular fat and glycolytic potential in muscle. Cluster analysis showed that studied pigs had been divided into three metabolic type groups differed significantly in plasma leptin, triglycerides, total and LDL cholesterol concentration, backfat thickness, glycolytic potential and drip loss.
\end{abstract}

KEY WORDS: pigs, leptin, lipid fractions, glycolytic potential, intramuscular fat, meat quality

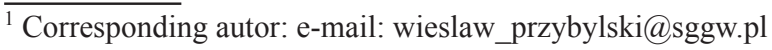




\section{INTRODUCTION}

In Europe pork is the very important meat that shows high their consumption, so its quality is very important aspect of interest. This is known that pork meat quality depends on genetic and environmental factors, which influenced on technological and sensory quality, mainly by glycogen content of slaughter and amount of intramuscular fat (Rosenvold and Andersen, 2003). On the other hand glycogen influences on ultimate $\mathrm{pH}$ that determined many meat quality traits as colour, drip loss, cooking loss and sensory atributes. Intramuscular fat (IMF) and colour are the strongest visual discriminative stimulus entering the decision by making process and loin chops with a low or medium amount of marbling (higher acceptability) (Przybylski et al., 2007). Pork IMF has been reported as positively influences on juiciness, tenderness and meat flavour. As was shown previously IMF was also related to breed, $\mathrm{MI}^{+}$(IMF/HFABP) gene, meat level in carcass, slaughter weight and feeding of animals during growing period (Rosenvold and Andersen, 2003). Despite the genetically determination of both traits, the mechanism of accumulation of fat and glycogen in muscle tissue is still partially known and not fully understood (Roehe et al., 2003). Presently improvement of meat quality by increasing the IMF level in muscles in breeding programs is one of the main purpose in European countries (Rosenvold and Andersen, 2003), because improvement of meatiness has caused in decreasing of sensory pork quality.

The many candidate genes were found to be associated with growth and obesity in pigs (Roehe et al., 2003). In particular the identification of leptin genes and its receptors has led to increasing the knowledge of the control of feed intake and regulation of energy balance. A lot of studies was carried out that leptin was secreted from white adipocytes and resulted in decreasing of feed intake, decreasing of body weight, fat depots and an increasing of energy metabolism (Barb et al., 2001). Ramsay (2001) found that leptin promotes the partitioning of energy away from lipid secretion within adipose tissue by promoting lipolysis directly and indirectly by reduction the insulin-mediated lipolysis inhibition. The leptin receptor has been found to be polymorphic in different pork breeds and is thus the candidate gene for backfat deposition and daily gain in pigs. Leptin receptors interact with neuropeptides and neurotransmitters are known to be involved in feeding behaviour and energy-balance regulation. There are likely to make interactions between genes with roles in energy balance, nutrient partitioning, lipid and insulin metabolism and a variety of environmental effects such as stress, physical activity, diet composition, temperature, diseases and infection (Roehe et al., 2003).

The aim of the study was an analysis of meat quality traits, IMF and glycolitic potential (GP) relationship with plasma level of leptin and lipids and also analysis of variability above mentioned traits in P76 hybrids pigs from herd selected intensively for daily body weight gain and lean meat in carcass. 


\section{MATERIAL AND METHODS}

The research was carried out on 30 pigs (18 boars and 12 gilts) of P76-PenArLan hybrids line. This line has been created from Laconie (Large White, Hampshire and Pietrain breeds in equal proportions) and Penshire (Hampshire, Duroc and Large White breeds in following proportion: 50, 35 and 15\%) synthetic line. Research was realized on gilts and boars for getting of information to selection work because results obtained on castrated males they are inept. Animals were originated from breeding herd and were kept in group pens (4-5 pigs by pens, separately boars and gilts) equipped with automatic drinkers and fed ad libitum complete mixtures (from cereals with additives - mineral and vitamins). In the first period (25-65 kg body weight) the pigs received the following diet: 13.7 MJ $\mathrm{ME}, 169.08 \mathrm{~g}$ of crude protein and $10.41 \mathrm{~g}$ of lysine $/ \mathrm{kg}$. In the second period (65$100 \mathrm{~kg}$ ) the finisher diet was characterized by $13.58 \mathrm{MJ} \mathrm{ME}, 155.61 \mathrm{~g}$ of crude protein and $9.42 \mathrm{~g}$ of lysine $/ \mathrm{kg}$. One day before slaughter blood was taken from the anterior caval vein into heparinized tubes and centrifuging at $3000 \mathrm{rpm}$ for 10 min. Obtained blood plasma was transferred into vials and frozen at $-28^{\circ} \mathrm{C}$.

Plasma level of triglycerides (TG), total cholesterol (CHOL), HDL cholesterol was determined enzymatically using PTH Hydrex kits (Warsaw, Poland). LDL cholesterol was calculated according formula: $\mathrm{LDL}=\mathrm{CHOL}-(\mathrm{TG} / 5+\mathrm{HDL})$. Plasma leptin concentration was measured using the DSL (Webster, TX, USA) porcine leptin IRMA (DSL-82100) kit. Assays were performed as per the manufacturer's instructions with sensitivity $0.05 \mathrm{ng} / \mathrm{ml}$.

On the next day the animals were slaughtered in the slaughterhouse situated 50 $\mathrm{km}$ from the farm, according to the following conditions: the rest time- two hours of pre-slaughter, automatic electric stunning and exsanguinations in the horizontal position, carcass was chilled in fast cooling system. The backfat thickness and loin thickness was determined by using CGM apparatus and on this basis meat percent in carcass was calculated. Meat quality parameters were evaluated in samples of the Longissimus dorsi (LD) muscle taken behind the last rib. The $\mathrm{pH}$ value was measured in 1 and $24 \mathrm{~h}$ after slaughter directly in the muscle tissue. Meat colour was measured in CIE L*a*b* system by Minolta CR310 chromameter in $48 \mathrm{~h}$ post mortem. The natural drip loss was determined according to Prange (1977) methods, the fat in muscle according to Soxhlet method (PN-73/A-85111). In LD glycogen, glucose and glucose-6-phosphate after glycogen hydrolysis with amyloglucosidase (Dalrymple and Hamm, 1973) and lactate (Bergmeyer, 1974) were determined. On the basis of them the glycolytic potential (GP) was calculated according to Monin and Sellier (1985).

Data were analysed using Statistica 6.0 Pl system (StatSoft, Inc., 2001). T-students test was applied to verifications the differences between boars and gilts. The simple correlations between measured traits were also calculated. The cluster analysis (as main exploration data methods) with k-means procedures was used. 
This method enables grouping of similar elements to similar classes for purpose of discovering of structure of data. Differences between selected groups were verified by analysis of variance. In cluster analysis as criteria of distribution was applied the meat quality traits and plasma leptin and lipids concentration.

\section{RESULTS}

The results for production traits (meatiness and meat quality) showed that studied pigs were characterized by high meatiness (about $60 \%$ of meat in carcass) and simultaneously appropriate meat quality. In the examined fatteners, neither PSE (pale, soft, exudative) or acid meat were observed. The results confirmed that P76 is adequate line for crossbreeding giving fatteners with high meatiness and good meat quality. Results showed a lack of differences between boars and gilts (in all traits characterized slaughter and meat quality values and plasma lipid parameters) except the level of leptin which was significantly higher in tested boars (Tables 1 and 2).

Table 1. Characteristics of slaughter value and meat quality of P76 pigs dependency to sex

\begin{tabular}{lccr}
\hline Traits & Boars & Gilts & SEM \\
\hline Number of animals & 18 & 12 & \\
Body weight, kg & 106.89 & 112.60 & 2.35 \\
Age, days & 154.11 & 147.00 & 2.84 \\
Average daily gain, g/day & 704.94 & 786.95 & 29.23 \\
Hot carcass weight, kg & 84.38 & 89.14 & 1.63 \\
Meat in carcass, \% & 59.98 & 60.41 & 0.30 \\
Loin thickness, mm & 63.83 & 67.36 & 0.87 \\
Backfat thickness, mm & 11.78 & 12.64 & 0.43 \\
$\mathrm{pH}_{1}$ & 6.35 & 6.40 & 0.05 \\
pH ${ }_{24}$ & 5.60 & 5.62 & 0.01 \\
Intramuscular fat level, \% & 1.58 & 1.34 & 0.21 \\
Glycolytic potential of LD muscle, $\mu$ mol/g & 128.88 & 129.88 & 3.10 \\
Colour L & 54.97 & 55.42 & 0.31 \\
$\quad$ A & 16.17 & 15.92 & 0.16 \\
$\quad$ B & 9.33 & 9.07 & 0.14 \\
Drip loss, \% & 3.80 & 3.07 & 0.32 \\
\hline
\end{tabular}

Table 2. Leptin and lipids fraction in blood plasma in boars and gilts of P76 pigs

\begin{tabular}{lccc}
\hline Traits & Boars & Gilts & SEM \\
\hline Number of animals & 18 & 12 & \\
Leptin, $\mathrm{ng} / \mathrm{ml}$ & $52.46^{\mathrm{a}}$ & $35.62^{\mathrm{b}}$ & 2.96 \\
TG, $\mathrm{mg} / 100 \mathrm{ml}$ & 21.42 & 20.62 & 1.53 \\
Total cholesterol, $\mathrm{mg} / 100 \mathrm{ml}$ & 98.37 & 95.62 & 2.42 \\
Cholesterol HDL, $\mathrm{mg} / 100 \mathrm{ml}$ & 28.56 & 28.66 & 0.92 \\
Cholesterol LDL, $\mathrm{mg} / 100 \mathrm{ml}$ & 65.52 & 62.83 & 2.64 \\
\hline
\end{tabular}

$\mathrm{a,b}-\mathrm{P} \leq 0.05$ 
Analysis of relationship between studied traits showed the significant inversely correlation between plasma leptin concentration and backfat thickness (Figure 1). The significant relationship between IMF and GP $(r=-0.35 ; \mathrm{P} \leq 0.05)$ in muscle tissue (Figure 2) was also found.

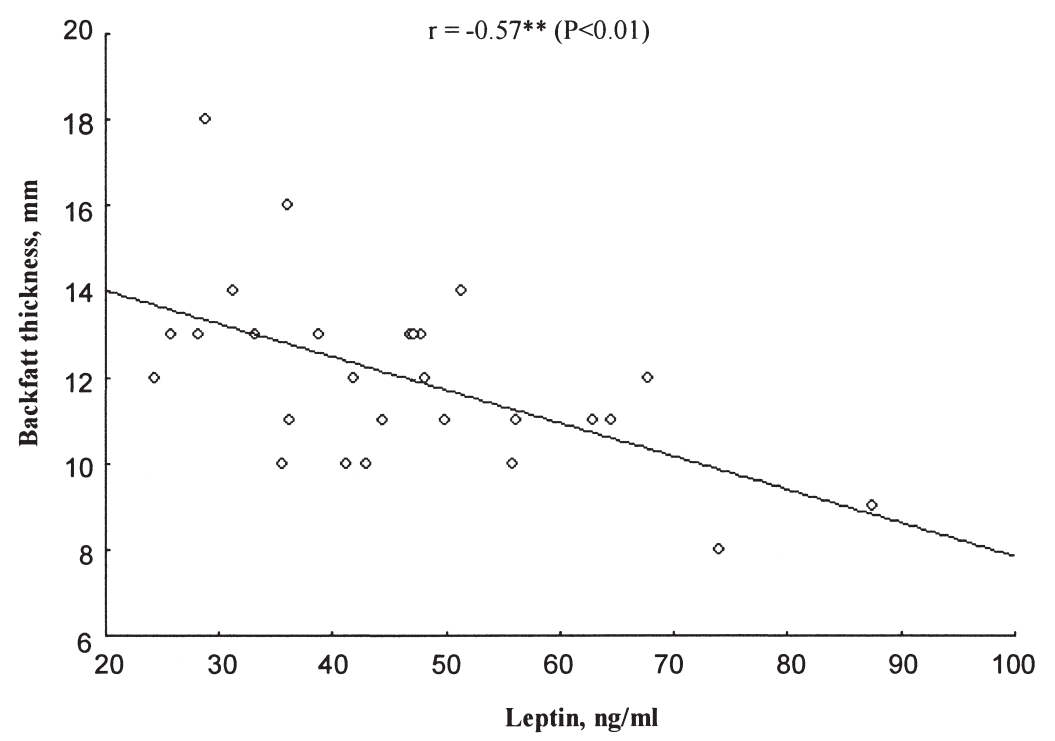

Figure 1. The relationship between backfat thickness and plasma leptin

Cluster analysis showed that studied populations it has been divided on three groups significantly differed in leptin, TG, CHOL and LDL level in plasma, back fat thickness, GP in LD muscle and drip loss (Table 3).

As it present in Table 3 in first group they were mainly boars and in second and third boars with gilts. The most numerous group was characterized by low plasma leptin and TG level of content, low level of IMF in muscle tissue, higher daily gain, high GP and average drip loss, rather high CHOL and LDL plasma concentration and simultaneously the highest backfat thickness (Table 3). The third group was characterized by highest level of leptin, lipids and was also characterized by the lowest backfat thickness, high GP, IMF and drip loss. The contrary situation in the first group (mainly consists of boars) has been observed in which high leptin and low TG, CHOL and LDL plasma concentration accompanied by low average daily gain, GP, drip loss, backfat thickness and IMF was found (Table 3 ). The obtained results of the two groups (1 and 3) by cluster analysis indicated that higher level of leptin was observed in the group with lower average daily body weight gain which confirms leptin influence on feed intake. In presented study a significant differences between groups in glycogen muscle level, backfat thickness and significant relationship between IMF and GP were 


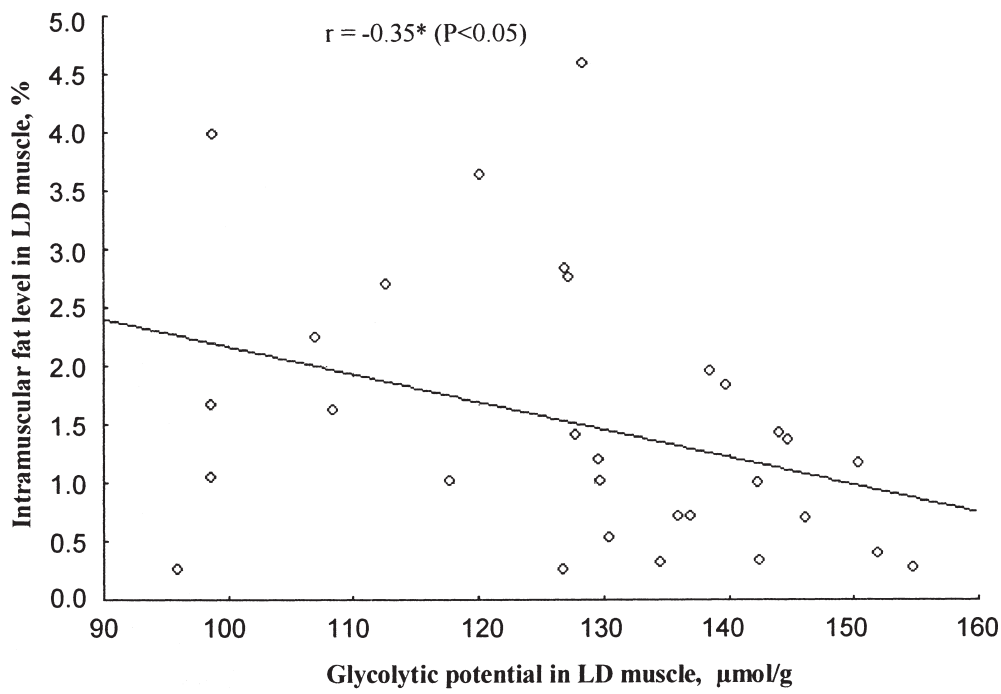

Figure 2.The relationship between intramuscular fat level and glycolytic potential in Longissimus dorsi muscle

Table 3. Results of aggregation analysis in studied group of P76 pigs

\begin{tabular}{|c|c|c|c|c|}
\hline \multirow{2}{*}{ Traits } & \multicolumn{3}{|c|}{ Cluster number } & \multirow{2}{*}{ SEM } \\
\hline & 1 & 2 & 3 & \\
\hline Number of animals & 9 & 14 & 7 & \\
\hline Boars & 8 & 6 & 4 & \\
\hline Gilts & 1 & 8 & 3 & \\
\hline Leptin, ng/ml & $51.65^{\mathrm{a}}$ & $38.47^{\mathrm{b}}$ & $56.61^{\mathrm{a}}$ & 2.96 \\
\hline $\mathrm{TG}, \mathrm{mg} / 100 \mathrm{ml}$ & $18.81^{\mathrm{a}}$ & $19.50^{\mathrm{a}}$ & $29.51^{\mathrm{b}}$ & 1.53 \\
\hline Total cholesterol, mg/100 ml & $87.40^{\mathrm{a}}$ & $101.10^{\mathrm{b}}$ & $105.54^{\mathrm{b}}$ & 2.42 \\
\hline Cholesterol HDL, mg/100 ml & 30.49 & 27.82 & 27.22 & 0.92 \\
\hline Cholesterol LDL, mg/100 ml & $53.14^{\mathrm{a}}$ & $69.38^{\mathrm{b}}$ & $72.41^{\mathrm{b}}$ & 2.64 \\
\hline Hot carcass weight, $\mathrm{kg}$ & 81.62 & 89.89 & 85.46 & 1.63 \\
\hline Average daily gain, $g /$ day & 661.21 & 778.44 & 714.98 & 29.23 \\
\hline Meat in carcass, $\%$ & 60.44 & 59.98 & 60.28 & 0.30 \\
\hline Loin thickness, $\mathrm{mm}$ & 64.00 & 66.85 & 62.60 & 0.87 \\
\hline Backfat thickness, mm & $11.11^{\mathrm{a}}$ & $13.08^{\mathrm{b}}$ & $10.80^{\mathrm{a}}$ & 0.43 \\
\hline $\mathrm{pH}_{1}$ & 6.26 & 6.42 & 6.52 & 0.05 \\
\hline $\mathrm{pH}_{24}$ & 5.59 & 5.61 & 5.62 & 0.01 \\
\hline Intramuscular fat level, $\%$ & 1.85 & 1.04 & 2.20 & 0.21 \\
\hline Glycolytic potential of LD m., $\mu \mathrm{mol} / \mathrm{g}$ & $113.63^{\mathrm{a}}$ & $137.04^{b}$ & $135.22^{\mathrm{b}}$ & 3.10 \\
\hline Colour L & 53.55 & 55.78 & 55.90 & 0.31 \\
\hline $\mathrm{a}$ & 16.52 & 15.85 & 16.10 & 0.16 \\
\hline $\mathrm{b}$ & 8.94 & 9.37 & 9.53 & 0.14 \\
\hline Drip loss, $\%$ & $2.68^{\mathrm{a}}$ & $3.37^{\mathrm{ab}}$ & $4.86^{\mathrm{b}}$ & 0.32 \\
\hline
\end{tabular}


shown. These results suggest that pigs from three different groups had different metabolic type, i.e. different total glycogen and fat content and meat quality also.

\section{DISCUSSION}

High meatiness and appropriate meat quality in studied pigs probably it was a result of the elimination of the stress sensitivity gene and RN gene from PenArLan herds (Przybylski et al., 2007).

Total cholesterol level in blood plasma in pigs obtained in this experiment was higher than results of Sechman et al. (2007) and Yu et al. (2007). As was discussed by Sechman et al. (2007) the plasma lipoprotein profile in pigs varies according to not only feed components but also sex and race. HDL fractions was lower and LDL was higher in comparison to results obtained by Scheman et al. (2007). On the other hand similar TG, HDL, LDL level and HDL/LDL ratio was observed in this study and those had obtained by Yu et al. (2007) and Fernández-Figares et al. (2007). Yu et al. (2007) observed a lower TG level in pigs with low IMF level in muscle and in contrary the pigs with higher LDL and TG level had higher IMF in LD muscle.

Sex-related differences in plasma leptin concentration were observed in this study and are in contrary to many studies showing a higher level of this hormone in female. These results are in close agreement to Berg et al. (2003) data, who observed higher leptin concentration in barrow's plasma that in gilt's. It was shown that stress hormones could be influenced on leptin secretion (Barb et al., 2001) and that boars are more aggressive in different situations. It should be also considered that in lean pigs group we obtained a negative relationship between backfat thickness and plasma leptin level. Some research showed that frequently in pigs with low backfat thickness the fat is deposed in other parts of body (Roehe et al., 2003). This could be one of explanation of the results obtained in this experiment. Also in the group with higher level of leptin the higher IMF in LD muscle was observed (Table 3).

Berg et al. (2003) reported that serum leptin concentrations were higher in obese pigs compared to non-obese animals. Barb et al. (2001) showed that low serum leptin concentration was not due to body fat deposition. Also Jiang and Gibson (1999) reported in their study a lack of association between polymorphism of the leptin gene and adiposity within four breed of pigs exhibiting high and low backfat thickness. Study of Maćkowiak et al. (2004) on three genetic groups of pigs showed the lowest concentration of the leptin in animals with highest subcutaneous fat deposition. Authors suggested that leptin secretion depends not only to body fat mass but to anabolic processes measured as daily weight gain and is correlated poorly with the expression of hypothalamic receptors for this hormone in the pig. In study of Fernández-Figares et al. (2007) in obese (Iberian) in comparison to lean (Landrace) growing gilts the higher leptin and lower triglycerides serum concentration as well as higher level of total cholesterol were 
found. Obese Iberian pigs (with higher level of leptin) was characterized also by higher diet intake which was explained as resistance to circulating leptin.

As was described by Pösö and Puolanne (2005) leptin had been shown to up regulate MCT1 isoform from monocarboxylate transporter (MCTs) transmembrane protein family, which co transport of protons together with a lactate anion. In addition also the to lactate, MCTs also facilitate the transport of other monocarboxylate anions, such as short chain fatty acids and ketone bodies, through cell membranes, and least isoform 8 (MCT8) is also involved in the transport of thyroid hormones into cells. In our results a significant inversely correlations between muscle glycogen level and IMF and in three groups between muscle glycolytic potential and plasma leptin level were presented. Hocquette et al. (1998) described in his review that pigs fed a high-protein and carbohydrates feed were characterized higher protein synthesis, total respiration and ATP production and lower intramuscular fat. These authors based on literature also concluded that selection to lean tissue growth increased sensitivity to insulin and may be influenced on glycogen deposition and the improvement of growth leads to animals with decreasing of intramuscular lipid.

Larzul et al. (1998) showed genetic correlations between glycolytic potential and other traits characterized carcass slaughter values and average daily body weight gain and speculated that improvement of this traits could be resulted in increasing of glycogen level in muscle. Other experiment of Larzul et al. (1995) with pigs selected to decrease the muscular glycolytic potential showed a significant diminution of this trait after four generations. In this experiment the indirect response on the backfat thickness were also observed as increasing of the adiposity in selected line. The genetic correlations between these traits have been estimated to $r=-0.60$. This could be related to decreasing of intramuscular fat observed in recent years. During this period an increasing of drip loss in meat that could be related to increasing in glycolytic potential in muscle was also observed. In present study a significant negative correlations between glycolytic potential and intramuscular fat was also demonstrated.

\section{CONCLUSIONS}

Obtained results showed the significant inversely relationship $\left(\mathrm{r}=-0.57^{*}\right)$ between plasma leptin level and backfat thickness and between intramuscular fat and glycolytic potential $\left(\mathrm{r}=-0.35^{*}\right)$ in skeletal muscle tissue. Cluster analysis showed that studied populations had been divided into three groups metabolic type different with significantly differences in plasma leptin, triglycerides, total and LDL cholesterol plasma concentration, backfat thickness, glycolytic potential in Longissimus dorsi muscle and drip loss. These results suggest that the amount of the adipose tissue, expressed as backfat thickness, is only one from many factors responsible for leptin secretion. 
Our results also showed that in studied pigs selected intensively for daily body weight gain and lean meat in carcass it is possible to observe groups with differences in energy balance regulation, lipids metabolism, muscle glycogen and fat deposition and meat quality.

\section{REFERENCES}

Barb C.R., Hausman G.J., Houseknecht K.L., 2001. Biology of leptin in the pig. Domest. Anim. Endocrinol. 21, 297-317

Berg E.P., McFadin E.L., Maddock K.R., Goodwin R.N., Baas T.J., Keisler D.H., 2003. Serum concentrations of leptin in six genetic lines of swine and relationship with growth and carcass characteristics. J. Anim. Sci. 81, 167-171

Bergmeyer H.U., 1974. Methods of Enzymatic Analysis. Academic Press, New York, pp. 1127, $1196,1238,1464$

Dalrymple R.H., Hamm R., 1973. A method for the extraction of glycogen and metabolites from a single muscle sample. J. Food Technol. 8, 439-444

Fernández-Figares I., Lachica M., Nieto R., Rivera-Ferre M.G., Aguilera J.F., 2007. Serum profile of metabolites and hormones in obese (Iberian) and lean (Landrace) growing gilts fed balanced or lysine deficient diets. Livest. Sci. 110, 73-81

Hocquette J.F., Ortigues-Marty I., Pethick D., Herpin P., Fernandez X., 1998. Nutritional and hormonal regulation of energy metabolism in skeletal muscles of meat-producing animals. Livest. Prod. Sci. 56, 115-143

Jiang Z.H., Gibson J.P., 1999. Genetic polymorphism in the leptin gene and their association with fatness in four pig breeds. Mamm. Genome 10, 191-193

Larzul C., Le Roy P., Gogué J., Talmant A., Vernin P., Lagant H., Monin G., Sellier P., 1995. Résultats de quatre générations de sélection sur le potentiel glycolytique musculaire mesuré in vivo. Journées Rech. Porcine, France 27, 171-174

Larzul C., Le Roy P., Sellier P., Jacquet B., Gogué J., Talmant A., Vernin P., Monin G., 1998. Le potentiel glycolytique du muscle mesuré sur le porc vivant: un nouveau critère de sélection pour la qualité de la viande? Journées Rech. Porcine, France 30, 81-85

Maćkowiak P., Nowak K.W., Kaczmarek P., Szydłowski M., Kamyczek M., Eckert R., Różycki M., Świtoński M., 2004. Leptin concentrations in blood and its hypothalamic binding are poorly related with amount of fat and growth rate in pigs. J. Anim. Feed Sci. 13, 153-162

Monin G., Sellier P., 1985. Pork of low technological quality with a normal rate of muscle $\mathrm{pH}$ fall in the immediate post-mortem period: The case of the Hampshire breed. Meat Sci. 13, 49-63

Pösö A.R., Puolanne E., 2005. Carbohydrate metabolism in meat animals. Meat Sci. 70, 423-434

Prange H., Juggrt L., Scharner E., 1977. Untersuchungen zur Muskel Fleischqualität beim Schwein. Arch. Exp. Vet. Med. 30, 235-248

Przybylski W., Sieczko L., Jaworska D., Czarniecka-Skubina E., Niemyjski S., 2007. Estimation of conditionality of pork sensory quality by using multivariate analysis. Arch. Tierzucht 50, 125-135

Ramsay T.G., 2001. Porcine leptin alters insulin inhibition of lipolysis in porcine adipocytes in vitro. J. Anim. Sci. 79, 653-657

Roehe R., Plastow G.S., Knap P.W., 2003. Quantitative and molecular genetic determination of protein and fat deposition. HOMO 54, 119-131

Rosenvold K., Andersen H.J., 2003. Factors of significance for pork quality - review. Meat Sci. 64, 219-237

Sechman A., Pieszka M., Rząsa J., Migdał W., Wojtysiak D., Pustkowiak H., Živković B., Paściak P., 2007. The effect of dietary conjugated linoleic acid on the levels of lipids, cholesterol and iodothyronines in the blood of pigs. J. Anim. Feed Sci. 16, 193-204

StatSoft, Inc., 2001. STATISTICA (data analysis software system), Version 6. www.statsoft.com

Yu I.T., King Y.T., Chen S.L., Wang Y.H., Chang Y.H., Yen H.T., 2007. Dietary conjugated linoleic acid and leucine improve pork intramuscular fat and meat quality. J. Anim. Feed Sci. 16, 65-74 